the Total Environment

Elsevier Editorial system(tm) for Science of

Manuscript Draft

Manuscript Number: STOTEN-D-18-06694

Title: Evaluation of four modelling approaches to simulate nitrous oxide emissions in China's cropland

Article Type: Research Paper

Keywords: nitrous oxide; model simulation; cropland; DAYCENT; DNDC; linear model

Corresponding Author: Dr. Kun Cheng, Ph.D.

Corresponding Author's Institution: Nanjing Agricultural University

First Author: Qian Yue

Order of Authors: Qian Yue; Kun Cheng, Ph.D.; Stephen Ogle; Jonathan Hillier; Pete Smith; Mohamed Abdalla; Jianfei Sun; Genxing Pan

Abstract: Process-based models are useful tools to integrate the effects of detailed agricultural practices, soil characteristics, mass balance, and climate change on soil N2O emissions in soil - plant ecosystems, whereas static, seasonal or annual models often exist to estimate cumulative N2O emissions under data-limited conditions. A study was carried out to compare the capability of four models to estimate seasonal cumulative fluxes from 425 field measurements of N2O emissions representing 67 studies across China's croplands. The models were 1) the DAYCENT model, 2) DeNitrification - DeComposition model (DNDC), 3) the linear regression model (LRM) of Yue et al. (2018), and 4) IPCC Tier 1 emission factors. The DAYCENT and DNDC models were estimated crop yields with R2 values of 0.60 and 0.66 respectively; but DNDC showed significant underestimation according to bias analysis. For seasonal cumulative N20 emission predictions, the correlation of modelled with measured N2O emissions had an R2 of $0.14,0.14,0.23$ and 0.15 for DAYCENT, DNDC, LRM of Yue et al. (2018), and IPCC, respectively. No significant bias was identified except for the significant underestimation of $0.52 \mathrm{~kg} \mathrm{~N} 20-\mathrm{N}$ ha-1 with the DNDC model. The modelled daily N2O emission against observations from the experimental fields indicated that the DAYCENT and DNDC models simulated temporal patterns effectively, although they did not capture the emission peaks perfectly. Based on RMSE and bias analysis, LRM performed well on N2O emission prediction for paddy rice fields, while DAYCENT performed well for wheat and IPCC for maize. All models simulated N2O fluxes well for soybeans, but not well for cotton or fallow. Moreover, DAYCENT and LRM performed well under different fertilizer management (no fertilizer, mineral fertilizer, and organic fertilizer), while DNDC significantly underestimated the emissions under no fertilizer and when organic fertilizer was applied, as did IPCC when organic fertilizer was applied.

Suggested Reviewers: Jamie Gerber University of Minnesota jsgerber@umn. edu 
Ute Skiba

Centre for Ecology and Hydrology

ums@ceh.ac.uk

Katja Klumpp

French National Institute for Agricultural Research

katja.klumppeinra.fr

Xiaotang Ju

China Agricultural University

juxtecau.edu.cn

Liping Guo

Chinese Academy of Agricultural Sciences

guoliping@caas.cn

Opposed Reviewers: 
Dear editors,

Herewith we are submitting a manuscript entitled "Evaluation of four modelling approaches to simulate nitrous oxide emissions in China's cropland", for review and potential publication in Science of the Total Environment. This manuscript provides an evaluation of four modelling approaches to simulate $\mathrm{N}_{2} \mathrm{O}$ emissions with 425 field measurements from China. We conclude that neither of the models emerged as a clear "best" choice for estimating $\mathrm{N}_{2} \mathrm{O}$ emissions for Chinese cropping systems.

This work has not been submitted or published elsewhere. The manuscript deals with the true results based on a newly established dataset of data collected from published literatures.

Please contact me if you have questions about the manuscript. We appreciate any consideration given to this manuscript for publication in Science of the Total Environment.

Sincerely,

Kun Cheng, Ph.D.

Institute of Resource, Ecosystem and Environment of Agriculture, Nanjing Agricultural University, 1 Weigang, Nanjing, Jiangsu 210095, China

Telephone: +862584399852

Email: kuncheng@aliyun.com; chengkun@njau.edu.cn 


\section{Evaluation of four modelling approaches to simulate nitrous oxide emissions in China's cropland}

Qian Yue ${ }^{\mathrm{a}, 1}$, Kun Cheng ${ }^{\mathrm{a}, 1, *}$, Stephen Ogle ${ }^{\mathrm{b}, \mathrm{c}}$, Jonathan Hillier ${ }^{\mathrm{d}}$, Pete Smith ${ }^{\mathrm{e}}$, Mohamed Abdalla ${ }^{\mathrm{e}}$, Jianfei Sun ${ }^{\mathrm{a}}$, Genxing Pan $^{\mathrm{a}}$

${ }^{\text {a }}$ Institute of Resource, Ecosystem and Environment of Agriculture, Nanjing

Agricultural University, 1 Weigang, Nanjing, Jiangsu 210095, China

${ }^{\mathrm{b}}$ Natural Resource Ecology Laboratory, Colorado State University, Fort Collins, CO 80523, USA

${ }^{\mathrm{c}}$ Department of Ecosystem Science and Sustainability, Colorado State University, Fort Collins, CO 80523, USA

${ }^{\mathrm{d}}$ Global Academy of Agriculture and Food Security, The Royal (Dick) School of Veterinary Studies and The Roslin Institute, Easter Bush Campus, Midlothian, EH25 9RG, UK

${ }^{\mathrm{e}}$ Institute of Biological and Environmental Sciences, School of Biological Sciences, University of Aberdeen, Aberdeen, AB24 3UU, UK

${ }^{1}$ These authors made equal contributions to this work.

*Corresponding author: Kun Cheng, Ph.D.

Address: Institute of Resource, Ecosystem and Environment of Agriculture, Nanjing Agriculture University, 1 Weigang, Nanjing, Jiangsu 210095, China

Tel.: +862584399852 Fax: +862584396507

Email: kuncheng@aliyun.com; chengkun@njau.edu.cn

Running head: Model comparisons for soil $\mathrm{N}_{2} \mathrm{O}$ emissions 

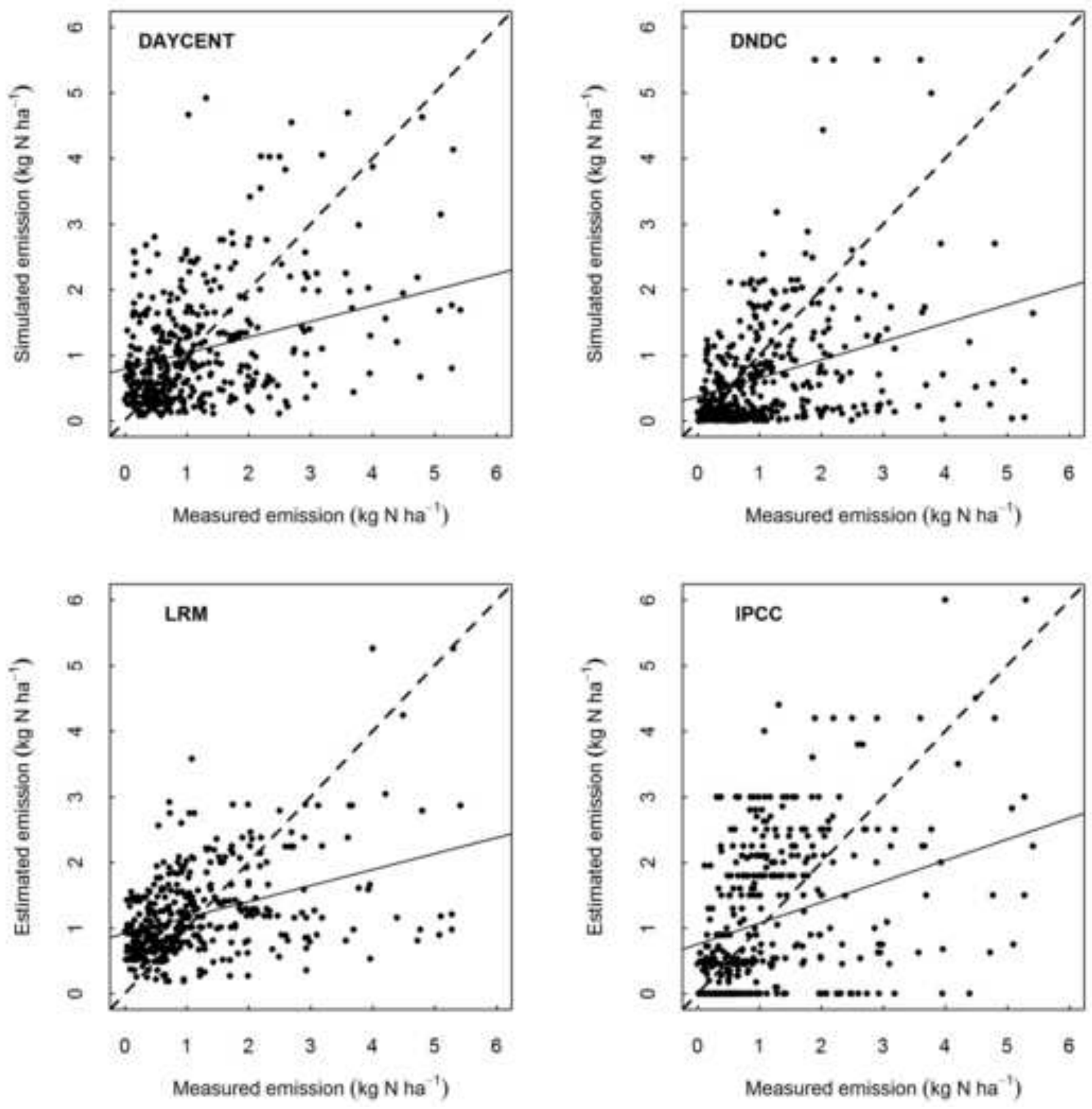
${ }^{*}$ Highlights (for review : 3 to 5 bullet points (maximum 85 characters including spaces per bullet point)

Highlights

1, DAYCENT, DNDC, linear regression model and IPCC tier 1 approach were evaluated to simulate $\mathrm{N} 2 \mathrm{O}$ emissions in China's cropland.

2, Neither of the models emerged as a clear "best" choice for estimating $\mathrm{N}_{2} \mathrm{O}$ emissions for Chinese cropping systems.

3, Further development is needed to represent regional conditions in China. 
1 Evaluation of four modelling approaches to simulate nitrous oxide 2 emissions in China's cropland

3 Abstract: Process-based models are useful tools to integrate the effects of detailed 4 agricultural practices, soil characteristics, mass balance, and climate change on soil $\mathrm{N}_{2} \mathrm{O}$ 5 emissions in soil - plant ecosystems, whereas static, seasonal or annual models often exist to estimate cumulative $\mathrm{N}_{2} \mathrm{O}$ emissions under data-limited conditions. A study was carried out to compare the capability of four models to estimate seasonal cumulative fluxes from 425 field measurements of $\mathrm{N}_{2} \mathrm{O}$ emissions representing 67 studies across China's croplands. The models were 1) the daily time-step version of CENTURY (DAYCENT), 2) DeNitrification DeComposition model (DNDC), 3) the linear regression model (LRM) of Yue et al. (2018), and 4) IPCC Tier 1 emission factors. The DAYCENT and DNDC models were estimated crop yields with $\mathrm{R}^{2}$ values of 0.60 and 0.66 respectively; but DNDC showed significant underestimation according to bias analysis. For seasonal cumulative $\mathrm{N}_{2} \mathrm{O}$ emission predictions, the correlation of modelled with measured $\mathrm{N}_{2} \mathrm{O}$ emissions had an $\mathrm{R}^{2}$ of $0.14,0.14$, 0.23 and 0.15 for DAYCENT, DNDC, LRM of Yue et al. (2018), and IPCC, respectively. No significant bias was identified except for the significant underestimation of $0.52 \mathrm{~kg} \mathrm{~N}_{2} \mathrm{O}-\mathrm{N}$ $\mathrm{ha}^{-1}$ with the DNDC model. The modelled daily $\mathrm{N}_{2} \mathrm{O}$ emission against observations from the experimental fields indicated that the DAYCENT and DNDC models simulated temporal patterns effectively, although they did not capture the emission peaks perfectly. Based on RMSE and bias analysis, LRM performed well on $\mathrm{N}_{2} \mathrm{O}$ emission prediction for paddy rice fields, while DAYCENT performed well for wheat and IPCC for maize. All models simulated $\mathrm{N}_{2} \mathrm{O}$ fluxes well for soybeans, but not well for cotton or fallow. Moreover, DAYCENT and LRM performed well under different fertilizer management (no fertilizer, mineral fertilizer, and organic fertilizer), while DNDC significantly underestimated the 
25 emissions under no fertilizer and when organic fertilizer was applied, as did IPCC when 26 organic fertilizer was applied.

27 Key words: nitrous oxide; model simulation; cropland; DAYCENT; DNDC; linear model 
Anthropogenic greenhouse gas (GHG) emissions, a major contributor to climate change (IPCC, 2013), have increased rapidly across the world by $41 \%$ from $38.2 \mathrm{Pg} \mathrm{CO}_{2}$ equivalent $\left(\mathrm{CO}_{2}\right.$-eq) in 1990 to $53.9 \mathrm{Pg} \mathrm{CO}$-eq in 2012 (http://edgar.jrc.ec.europa.eu/). The trend is projected to continue in coming decades as a result of increasing food demand and limited resources (Reay et al., 2012). Meanwhile, the Paris Agreement aims to limit global warming to "well below" 2 degrees Celsius, with an ambition to pursue efforts to limit warming to below 1.5 degrees Celsius, and many countries have already made commitments to participate towards achieving these goals. As one of the world's most populous countries, with $29.3 \%$ of the world's total emissions (Janssens-Maenhout, et al., 2017), China is of key importance for mitigating global emissions, and has recently pledged "no-increase" in chemical fertilizer and pesticide in order to achieve peak GHG emissions by the year 2030 (UNFCCC, 2015).

Nitrous oxide $\left(\mathrm{N}_{2} \mathrm{O}\right)$ has a global warming potential (GWP) of approximately 265-310 times that of carbon dioxide $\left(\mathrm{CO}_{2}\right)$ over a 100-year timescale (Watson et al., 1996; IPCC, 2007; IPCC, 2013) with an atmospheric lifetime of approximately 120 years (Prather, 1998). Global $\mathrm{N}_{2} \mathrm{O}$ emissions increased to $9.2 \mathrm{Tg} \mathrm{N}_{2} \mathrm{O}$ in 2012 from $5.4 \mathrm{Tg} \mathrm{N}_{2} \mathrm{O}$ in $1970 . \mathrm{N}_{2} \mathrm{O}$ contributes to secondary inorganic aerosol formation and thus haze pollution in addition to climate change (Liu et al., 2017). For China, $\mathrm{N}_{2} \mathrm{O}$ emissions accounted for $16.4 \%$ of global emissions (Janssens-Maenhout, et al., 2017). The most significant source of $\mathrm{N}_{2} \mathrm{O}$ emissions was agriculture, accounting for $51 \%$ of total national $\mathrm{N}_{2} \mathrm{O}$ emissions (FAO, 2015). Emissions from agriculture tripled from 0.36 to $1.21 \mathrm{Tg} \mathrm{N}_{2} \mathrm{O}$ in China between 1970 and 2014 (FAO, 2015). Given the importance of this source of emissions, reducing uncertainty in its estimation is an important issue for China to effectively identify ways to mitigate. 
The Intergovernmental Panel on Climate Change (IPCC) provided in 1997 (IPCC, 1997) a default global $\mathrm{N}_{2} \mathrm{O}$ emission factor intended for use in national inventories of $1.25 \%$ with the confidence interval of $0.25-2.25 \%$ for fertilizer-induced emission (FIE) from all cropland (IPCC, 1997). That is, that $1.25 \%$ of nitrogen applied in crop systems is released as $\mathrm{N}_{2} \mathrm{O}-\mathrm{N}$. This factor was subsequently updated to $1 \%$ with the confidence interval of $0.3-3.0 \%$ and $0.3 \%$ with the confidence interval of $0.0-0.6 \%$ (Tier I approach) from upland crops and paddy rice cultivation, respectively (IPCC, 2006). Generally, the emission factor approach makes it easy to calculate the FIE using applied $\mathrm{N}$ rate, but also leads to large uncertainties. Therefore, as recommended by the IPCC (2006), higher Tier methods should be developed to obtain more representative, country specific emission rates or spatially disaggregated $\mathrm{N}_{2} \mathrm{O}$-EFs that are region and crop-specific.

Linear or nonlinear regression models can be developed to estimate $\mathrm{N}_{2} \mathrm{O}$ emissions from croplands as a function of field and management variables based on field measurements (Bouwman et al., 2002; Gerber et al., 2016; Albanito et al., 2017). For example, Yue et al. (2018) published a China-specific multi-variate empirical model for $\mathrm{N}_{2} \mathrm{O}$ emissions to identify the spatial variability caused by the major drivers. On the other hand, process-based models have been widely used to estimate $\mathrm{N}_{2} \mathrm{O}$ emissions and potential effects of global climate change on the terrestrial ecosystems. Several dynamic process-based models have been developed to predict $\mathrm{N}_{2} \mathrm{O}$ emissions informed by an understanding of key soil processes and mechanisms (e.g. SUNDIAL by Smith et al., 1997; DNDC by Li et al., 1992; DAYCENT by Ogle et al., 2010). Compared to regression models, most process-based models simulate the emissions of several GHGs $\left(\mathrm{CO}_{2}, \mathrm{CH}_{4}, \mathrm{~N}_{2} \mathrm{O}\right)$ considering environmental and management related factors, such as crop growth, soil properties, fertilization and climate. DAYCENT and DNDC models are both widely-used ecosystem biogeochemistry models adopted to simulate $\mathrm{N}_{2} \mathrm{O}$ emissions all over the world (Abdalla et al., 2010). DAYCENT 
simulates C, N, P, K and S dynamics in plant-soil systems (Parton et al., 1998; Del Grosso et al., 2001). DNDC mainly focuses on nitrification and denitrification for $\mathrm{N}$ dynamics from upland soils and rice paddy systems (Li et al., 1992, 1994).

There are limitations and uncertainties in estimating $\mathrm{N}_{2} \mathrm{O}$ fluxes from process-based model simulations, associated with the representation of the mechanistic processes. Frolking et al. (1998) found that DNDC simulated very low $\mathrm{N}_{2} \mathrm{O}$ fluxes for a dry site in Colorado. In contrast, Smith et al. (2007) produced accurate predictions of average seasonal $\mathrm{N}_{2} \mathrm{O}$ emissions from the DNDC model for two sites in Eastern Canada, while the DAYCENT model underestimated $\mathrm{N}_{2} \mathrm{O}$ emissions. This variability in performance implies that model inter-comparisons are useful to determine the most appropriate application for a specific region or cropping system. For many countries, including China, model inter-comparisons are especially important since many process-based models, in spite of their intent to be generic, were originally calibrated on data from North-American or European cropping systems. The objective of this study is to compare the results of four models, namely DAYCENT, DNDC, LRM, IPCC, by calibrating and evaluating the $\mathrm{N}_{2} \mathrm{O}$ emission estimates under different cropping systems and $\mathrm{N}$ application rates across the major agricultural regions of China. 
DAYCENT, the daily time-step version of CENTURY, is a process-based ecosystem model developed to simulate carbon (C), N, P, K and S dynamics in plant-soil systems (Parton et al., 1998; Del Grosso et al., 2001). The nitrogen fluxes through the plant, residue and soil organic matter pools are coupled with $\mathrm{C}$ and estimated based on the $\mathrm{C}$ transfer between conceptual soil $\mathrm{C}$ pools, and the $\mathrm{C}: \mathrm{N}$ ratio of organic matter. The model considers symbiotic and asymbiotic $\mathrm{N}$ fixation, and fertilizer additions. Losses of $\mathrm{N}$ occur through removal of vegetation, nitrification, denitrification, $\mathrm{NH}_{3}$ volatilization, leaching and run-off. Daily weather data, essential management events, and soil texture data are needed as model inputs (Table 1). For our study, historical runs were performed to initialize the model in accordance with China-specific conditions (details are described in Cheng et al. (2014)).

The DeNitrification - DeComposition model (DNDC), contains four main sub-models as follows: the soil climate sub-model calculating hourly and daily soil temperature and moisture fluxes in one dimension; the crop growth sub-model simulating crop biomass accumulation and partitioning; the decomposition sub-model calculates decomposition, nitrification, $\mathrm{NH}_{3}$ volatilization and $\mathrm{CO}_{2}$ production; and the denitrification sub-model tracking the sequential biochemical reduction from nitrate $\left(\mathrm{NO}_{3}\right)$ to $\mathrm{NO}_{2}{ }^{-}, \mathrm{NO}, \mathrm{N}_{2} \mathrm{O}$ and $\mathrm{N}_{2}$ (Li et al., 1992; Li et al., 2000; Abdalla et al., 2010). Version 9.5 of the DNDC model was applied in the present study (http://www.dndc.sr.unh.edu/). The input data required were the same as for DAYCENT (Table 1).

A linear regression model approach has also been applied, named as LRM, fitting cumulative $\mathrm{N}_{2} \mathrm{O}$ emissions (Cum $\mathrm{N}_{2} O$ ) in $\mathrm{kg} \mathrm{N} \mathrm{ha}^{-1}$ season $^{-1}$ based on the following equation: 
118

where $N$ rate represents the nitrogen fertilizer application in $\mathrm{kg} \mathrm{N} \mathrm{ha}^{-1}$; Temp is the annual average temperature $\left({ }^{\circ} \mathrm{C}\right)$; Clay indicates the fraction of clay $(\%)$; values of $\beta_{1}$ for the different crop type classes are 0 for legume, 0.700 for upland crops, -0.188 for rice; and values of $\beta_{2}$ for the different base fertilizer are 0 for mineral fertilizer and -0.002 for organic fertilizer, and 0 for no fertilizer applied. The required data are $\mathrm{N}$ fertilizer application rates, annual average temperature, soil clay content, crop type, and fertilizer type (Table 1).

Finally, using the IPCC default method (2006), annual cumulative $\mathrm{N}_{2} \mathrm{O}$ emissions $\left(\right.$ Cum $\left.\mathrm{N}_{2} \mathrm{O}\right)$ in $\mathrm{kg} \mathrm{N} \mathrm{ha}^{-1}$ year $^{-1}$ are calculated using the following equation:

\section{Cum $\mathrm{N}_{2} \mathrm{O}=\mathrm{N}$ rate $* E F$}

where $N$ rate represents the nitrogen fertilizer application in $\mathrm{kg} \mathrm{N} \mathrm{ha}^{-1}$; and values of $E F$ are 0.01 and 0.003 for upland crops and paddy rice cultivation, respectively. The only required data are $\mathrm{N}$ fertilizer rates (Table 1).

\subsection{Data sources}

$\mathrm{N}_{2} \mathrm{O}$ emissions data were collected during the crop growing season at the experimental sites $\left(\mathrm{kg} \mathrm{N} \mathrm{ha}^{-1}\right.$ season $\left.^{-1}\right)$ - defined as the period from planting to harvest for a given crop. We conducted a literature search in the databases: CNKI, ISI-Web of Knowledge and Google Scholar, with the search words "nitrous oxide", "emission", "chamber", and "China". A total of 134 papers were found and processed according to the publication date, journal category and data integrity. For these papers, a dataset of 67 studies with a total of 425 field $\mathrm{N}_{2} \mathrm{O}$ emission measurements were compiled. The dataset included the following information: cumulative $\mathrm{N}_{2} \mathrm{O}-\mathrm{N}$ emissions; grain yields; geographic information; soil characteristics including clay content, $\mathrm{C}$ and $\mathrm{N}$ content, bulk density, and $\mathrm{pH}$; cropping system; management 
practices; crop types - maize (MA), wheat (WH), rice paddy (RP), soybean, cotton, rape, and fallow; and fertilizer types classified into 5 broad categories - Control, Mineral, Organic, Mineral \& Organic (M_O), Controlled-release fertilizer or Nitrification inhibitor (more detailed information is provided in Table S1). All data were used to test DAYCENT, DNDC, and the EF method of IPCC. It should be noted that $267 \mathrm{~N}_{2} \mathrm{O}$ field emission measurements of the whole database (425 measurements) were used to derive the linear regression model of Qian et al. (2018), with all the measurements used to test the LRM of Qian et al. (2018), so the LRM model is not entirely independent of the evaluation data.

Most of the soil, crop, and cultivation management data were obtained from the dataset. However, missing soils data that were not provided in the papers were extracted from China Soil Scientific Database (http://www.soil.csdb.cn/) based on the soil type documented for the experimental site. Similarly, missing daily weather data, including daily maximum/minimum temperature and precipitation, were obtained from the China Meteorological Data Sharing Service System (http://new-cdc.cma.gov.cn:8081/home.do) for the station nearest to the reported site. Regional nitrogen deposition data were based on Xu et al. (2015).

For the process-based models, most of the parameters were based on prior research (DAYCENT with information from Cheng et al., 2014; DNDC from Abdalla et al., 2010). Crop growth directly controls soil water and $\mathrm{C}$ and $\mathrm{N}$ regimes, and hence is crucial for a biogeochemical model to correctly simulate trace gas flues, such as $\mathrm{N}_{2} \mathrm{O}$ (Hu et al., 2017). PRDX (the maximum potential production parameter), a dimensionless constant, was optimized by simulating crop yields in the range of 1-3 for DAYCENT for each of the experimental sites. Similarly, the indices of maximum biomass production, biomass fraction, and biomass $\mathrm{C} / \mathrm{N}$ ratio of grain, leaf, stem, and root distributions were optimized for yield simulations of field conditions for DNDC. 
DAYCENT and DNDC simulation results were evaluated against field measurements of $\mathrm{N}_{2} \mathrm{O}$ emissions by comparing the association between measured and modelled temporal patterns of $\mathrm{N}_{2} \mathrm{O}$ fluxes, as well as comparing the coincidence between measured and modelled emission values. Five representative benchmark sites were selected from the major regions of China to conduct the model evaluation of daily $\mathrm{N}_{2} \mathrm{O}$ emissions under typical cropping systems (Table 3). Daily measured emission values for model evaluation were extracted either directly from tables or text, or were extracted from the figures using Getdata Graph Digitizer software (http://www.getdata-graph-digitizer.com/).

\subsubsection{Model accuracy}

Cumulative $\mathrm{N}_{2} \mathrm{O}-\mathrm{N}$ fluxes were estimated as the sum of simulated daily fluxes for DAYCENT and DNDC models, and directly by LRM and IPCC. Model accuracy was evaluated by calculating the bias and root-mean-squared error (RMSE) between measured and modelled values using the following equations:

$$
R M S E=\sqrt{\left(\sum_{i=1}^{n}\left(\widehat{V}_{l}-V_{i}\right)^{2}\right) / n}
$$

where, $\widehat{V}_{l}$ and $V_{i}$ represent the estimated value of the target variable from the fitted equation and the measured value from the original studies; $\bar{V}$ is the mean of the observed data; $n$ is the number of target values; $p$ is the number of parameters in the relevant model; and $i$ is a single observation.

With the estimated Bias, the t-statistic was used to test for significant differences between 
188 were also calculated to evaluate model performance for each fertilizer and crop type 189 individually. All the statistical analyses were conducted in R version 3.4 .0 (2018) and 190 Microsoft Excel 2013.

191 
The measured yield data included 283 individual observations (Fig. 1), which ranged from 400 to $15700 \mathrm{~kg} \mathrm{ha}^{-1}$. The modelled yields ranged from 537 to $16657 \mathrm{~kg} \mathrm{ha}^{-1}$ for DAYCENT, and from 548 to $17230 \mathrm{~kg} \mathrm{ha}^{-1}$ for DNDC. The regression of modelled versus measured yields had $\mathrm{R}^{2}$ values of 0.60 and 0.66 , bias estimates of -823 and $-578 \mathrm{~kg} \mathrm{ha}^{-1}$, and RMSE values of 2201 and $2088 \mathrm{~kg} \mathrm{ha}^{-1}$ for DAYCENT and DNDC, respectively (Table 2). Both models had a significant relationship with observed values based on different crop types (Fig. 1), but there were significant differences from the measured values according to t-tests (Table 2).

201

\subsection{Daily $\mathrm{N}_{2} \mathrm{O}$ emission validation}

202

Seasonal patterns of daily $\mathrm{N}_{2} \mathrm{O}$ emissions were analysed for 5 sites with latitudes between $28.6^{\circ}$ to $47.4^{\circ}$ and longitudes from $113.3^{\circ}$ to $126.6^{\circ}$ (Table 3 ), representing several different climate regions and most common cropping systems in China. Seasonal emission patterns simulated by the DNDC and DAYCENT models were generally similar to the observed values for most of the experimental period. Also, a significant increasing trend in $\mathrm{N}_{2} \mathrm{O}$ emissions was simulated with increasing $\mathrm{N}$ application rates, corresponding with experimental observations. Both DAYCENT and DNDC models failed to model the specific timing and magnitude of daily $\mathrm{N}_{2} \mathrm{O}$ emission peaks. Overall, the DNDC model overestimated emissions on days with high precipitation by a factor of around 2, particularly at the upland sites (Fig. 2c and 2d). The DAYCENT model overestimated the fluxes upon drainage of rice cultivation systems (Fig. 2a, 2b and 2e).

\subsection{Cumulative $\mathrm{N}_{2} \mathrm{O}$ emission validation}

214 The observed emissions from 425 field $\mathrm{N}_{2} \mathrm{O}$ emission measurements across 67 studies (Fig. 1)

215 ranged from 0 to $11.14 \mathrm{~kg} \mathrm{~N} \mathrm{ha}^{-1}$ with $\mathrm{N}$ fertilizer applied in the range of $0-600 \mathrm{~kg} \mathrm{~N} \mathrm{ha}^{-1}$. 
216 The regression of modelled versus observed emissions had an $\mathrm{R}^{2}$ of 0.14 for both DAYCENT

217 and DNDC model, 0.23 for LRM, 0.15 for IPCC (Table 1, Fig. 3). Moreover, the LRM had

218 the lowest RMSE and bias with the values of 1.22 and $-0.02 \mathrm{~kg} \mathrm{~N} \mathrm{ha}^{-1}$, respectively; the

219 DNDC model had the highest RMSE of $1.48 \mathrm{~kg} \mathrm{~N}^{-1}$ and bias of $-0.52 \mathrm{~kg} \mathrm{~N}^{-1}$ (Table 1).

220 According to the t-test, the DNDC model results were significantly different from the observed values, but estimated values were not significantly different from observations for the other three models (Table 1).

\subsection{Model accuracy}

We also assessed the impacts of the simulated $\mathrm{N}_{2} \mathrm{O}$ emissions for different fertilizer and crop types, and observed that the accuracy of the four models differed (Table 4). The DAYCENT model estimated $\mathrm{N}_{2} \mathrm{O}$ emissions from mineral and organic fertilizer types with the lowest RMSE and bias, and did not differ significantly from the measured values. Conversely, the IPCC significantly overestimated the emissions with organic fertilization but estimated $\mathrm{N}_{2} \mathrm{O}$ emissions with low RMSE and bias for mineral fertilizers. In fact, only the DNDC model significantly underestimated the emissions under the mineral fertilizer treatments. The estimated values from all models showed significant differences compared to measured values under the control treatment with no $\mathrm{N}$ inputs. For crop types (Table 5), the LRM performed well for rice and maize cultivated system, as did the IPCC method for maize, and the DAYCENT model for wheat. Moreover, all models simulated emissions for soybean well, but none performed particularly well for cotton and fallow.

$\mathrm{N}$ management, and particularly additions, are the most important drivers of soil $\mathrm{N}_{2} \mathrm{O}$ emissions (Del Grosso et al., 2009). Given this fact, we further compared the correlations of $\mathrm{N}$ addition rates with observed emission values for the models (Fig. 4; Table 6). Both the modelled and observed values had a similar response to fertilizer application rate. The modelled values were higher in the paddy rice system (Fig. 4a) and were lower in the upland 
241 cropping system (Fig. 4b) compared to the measured values at low $\mathrm{N}$ application rates. The

242 range of the slopes were $0.0018-0.0042$ and $0.0039-0.0056$ for paddy rice and upland 243 cropping systems, respectively. 
246 Given the recognised difficulty in estimating $\mathrm{N}_{2} \mathrm{O}$ emissions precisely and the ongoing 247 challenge of developing models which perform over a wide range of conditions, model intercomparisons are an important way to determine a best candidate model for a given region and to identify potential ways to reduce the uncertainties. Model inter-comparisons have 250 previously been carried out in several countries (Frolking et al., 1998; Smith et al., 2007; 251 Abdalla et al., 2010).

Reasonable simulation of crop yield is of key importance to accurately predict $\mathrm{N}_{2} \mathrm{O}$ emissions for process-based models of plant-soil systems. The two process-based models, DAYCENT and DNDC, performed well in simulating crop yield, explaining 64\% of the variation in observed yields with DAYCENT and 71\% with DNDC (Table 2, Fig. 1). However, both models significantly underestimated yields by 823 and $578 \mathrm{~kg} \mathrm{ha}^{-1}$ for DAYCENT and DNDC, respectively, as indicated by the bias and t-test (Table 2). Previous studies have demonstrated reasonably accurate and precise predictions of crop yields in China for both DAYCENT and DNDC models (Cheng et al., 2013; Qiu \& Wang, 2012). However, some studies suggested some bias in model simulations. For example, Cheng et al. (2014) found that the DAYCENT model underestimated corn yields by $521.59 \mathrm{~kg} \mathrm{ha}^{-1}$, and Cui et al. (2014) found that the DNDC model underestimated the plant biomass for cotton. The bias in DNDC may be associated with the fact that DNDC does not simulate phosphorus and potassium impacts on production. In addition, the climate data used for the two process-based models includes only the maximum/minimum temperature and precipitation, which also might result in uncertainties for model simulation, and may be improved if other climate variables were addressed, such as the influence of humidity on transpiration rates and water stress. We found that the simulated yield varies greatly between control and fertilized plots for DAYCENT, which resulted in large bias compared with measured values. Production algorithms in 
DAYCENT may be too sensitive to N availability. Sansoulet et al. (2014) also found that DAYCENT was less effective at predicting biomass under limited $\mathrm{N}$ rates compared to DNDC.

In general, the models were able to simulate the daily flux over time; however, there were some abnormal peak periods of emissions simulated by both models, compared to the observed emissions. Specifically, $\mathrm{N}_{2} \mathrm{O}$ emission peaks often appeared in simulated upland crops of maize and wheat after heavy rainfall events for DNDC (Fig. 2c-2e), indicating $\mathrm{N}_{2} \mathrm{O}$ emissions are highly sensitive to soil moisture dynamics in the models (Lessard et al., 1996; Frolking et al. 1998; Smith et al., 2002). In addition, Smith et al., (2008) observed that DAYCENT and DNDC models both had difficulty in capturing soil water content accurately. Soil moisture dynamics are linked to soil texture. Groffman and Tiedje (1989) suggested that the smaller average pore size in finer textured soils leads to greater soil water retention and greater opportunity to create anaerobiosis, while denitrification occurs at lower rates in a well-drained coarse-textured soil (Bouwman et al., 2002a, 2002b). Thus, there may be an opportunity to further resolve the relationship between soil texture and water-filled pore space, and improve model predictions. Also, the accuracy of capturing $\mathrm{N}_{2} \mathrm{O}$ emission peaks may be associated with the frequency of sampling, with low frequency sampling (e.g., once a week or month) missing some of the peaks that are captured by the models.

In general, the four models explained $14 \%$ 23\% of the variation in observed seasonal cumulative $\mathrm{N}_{2} \mathrm{O}$ emissions. $\mathrm{N}_{2} \mathrm{O}$ emissions are inherently difficult to predict precisely for reasons stated above; however, this does suggest considerable opportunity for improvement. Nevertheless, no significant bias was identified except for the significant bias of $-0.52 \mathrm{~kg} \mathrm{~N}$ $\mathrm{ha}^{-1}$ for the DNDC model (Table 2). Beheydt et al. (2007) reported an overestimation of 7.4 $\mathrm{kg} \mathrm{N} \mathrm{N}_{2} \mathrm{O}-\mathrm{N} \mathrm{ha}{ }^{-1}$ for DNDC based on 22 long-term $\mathrm{N}_{2} \mathrm{O}$ field experiments. In addition, other research found that DAYCENT performed better than in this study, with an R-squared of $78 \%$ 
which was much higher than the value found in this study (Cheng et al., 2014). In this study we used more field measurements than Cheng et al. (2014), which may have added heterogeneity and uncertainty in model simulation. Conversely, Abdalla et al. (2010) indicated that DAYCENT performed poorly when simulating control plots, with $\mathrm{N}_{2} \mathrm{O}$ flux of $-57 \%$ below the measured values. Additionally, several studies have indicated that model accuracy varied for different fertilizer and cropping types (Smith et al., 2002; Cheng et al., 2014; Albanito et al., 2017). As shown, the DAYCENT model performs well with mineral and organic fertilizer types. The IPCC default method could only accurately predict emissions associated with mineral $\mathrm{N}$ fertilization, similar to results from Li et al. (2001).

DNDC did not accurately simulate $\mathrm{N}_{2} \mathrm{O}$ emissions associated with mineral fertilizer and paddy rice (Table 4, 5). In contrast, Smith et al. (2002) found the DNDC model prediction of $\mathrm{N}_{2} \mathrm{O}$ flux from control, manure, and mineral fertilization corresponded well with observed measurements from maize in Canada. Regardless, Li et al. (2017) reported that DNDC was not suitable for China as it lacks a number of features which are crucial for representing Chinese agro-ecosystems, especially paddy rice cultivation, complex and multiple cropping systems, and intensive management practices.

There are different target functions for the four models. The predictions of LRM and IPCC methods were more accurate and precise than the process-based models. While the LRM model was only used to calculate fertilizer-induced $\mathrm{N}_{2} \mathrm{O}$ emissions based on the underlying datasets that were used to derive these functions (and therefore not independent data), this does indicate that if a reasonably comprehensive dataset of $\mathrm{N}_{2} \mathrm{O}$ emissions exists for a given region, then better predictions will be obtained from a linear regression model than by calibrating and deploying a process-based model. The two process-based models, in theory, should be able to capture more heterogeneity and be applied across a broader range of croplands in China. One of the key strengths of DAYCENT is the initialization of SOM pools 
to accurately represent the carbon stocks, and the linkage between $\mathrm{C}$ and $\mathrm{N}$ flows through the plant-soil system. The $\mathrm{N}$ associated with carbon lost in respiration (30\% to $80 \%$ of the carbon flow is respired) is mineralized and becomes substrate of nitrification and denitrification (DAYCENT user manual). DNDC also has strengths related to fertilizer applications at varying depth, and a more mechanistic representation of $\mathrm{N}$ dynamics with Michaelis-Menten dynamics (Li et al., 2006).

Process-based models, such as DAYCENT and DNDC, can also represent more management impacts than empirical functions, particularly if data are limited for fitting a statistical model. For example, $\mathrm{Xu}$ et al. (2000) showed a significant effect of splitting fertilizer into three or more applications in DNDC, reducing $\mathrm{N}_{2} \mathrm{O}$ emissions by $25 \%$. Field practices of irrigation and tillage also influence $\mathrm{N}_{2} \mathrm{O}$ fluxes, and their impacts can be represented in these simulation models.

Our results indicated that the accuracy of model simulations may differ across a range of $\mathrm{N}$ rates. Cheng et al. (2014) showed DAYCENT tended to underestimate $\mathrm{N}_{2} \mathrm{O}$ emissions at higher measured emission rates, which were also seen for paddy rice in Fig. 4a. Albanito et al. (2017) studied $\mathrm{N}_{2} \mathrm{O}-\mathrm{EFs}$ and found that they tended to decrease with the $\mathrm{N}$ application rates approaching $1 \%$ in crops fertilized above $300 \mathrm{~kg} \mathrm{~N}^{-1}$, and the IPCC-EF would tend to underestimate $\mathrm{N}_{2} \mathrm{O}$ emissions by approximately $21 \%$ below a fertilization of $200 \mathrm{~kg} \mathrm{~N} \mathrm{ha}^{-1}$. Similarly, Shcherbak et al. (2014) indicated that the IPCC-EF would underestimate and overestimate $\mathrm{N}_{2} \mathrm{O}$ emissions in croplands fertilized above and below the threshold of approximately $150 \mathrm{~kg} \mathrm{~N} \mathrm{ha}^{-1}$. Sansoulet et al. (2014) also showed the different sensitivity under limited and high $\mathrm{N}$ rates. The negative intercept for DNDC might indicate that emissions are under-estimated with no fertilizer applied.

Environmental factors (especially climate) and human-induced activities (e.g. fertilizer, tillage, straw return, irrigation) influence $\mathrm{N}_{2} \mathrm{O}$ producing processes over both temporal and 
345 spatial scales, resulting in heterogeneous $\mathrm{N}_{2} \mathrm{O}$ emissions at field level (Flessa et al., 2002).

346 Cumulative seasonal $\mathrm{N}_{2} \mathrm{O}$ emissions based on the closed static chamber method were used in 347 most of the experiments at monthly or weekly intervals, which may lead to high inherent 348 variability of $\mathrm{N}_{2} \mathrm{O}$ fluxes. Ju et al. (2011) showed that a sampling frequency of 3 or 6 days led 349 to $112-236 \%$ overestimation of total $\mathrm{N}_{2} \mathrm{O}$ emissions. Process-based models may predict a flux 350 peak during times, such as after a rainfall event, which is not represented in observational 351 datasets with a low sampling frequency. Hence, an overestimation or underestimation of $352 \mathrm{~N}_{2} \mathrm{O}$ fluxes from upland soils may occur with static chambers, and more continuous 353 measurements will likely reduce uncertainties in evaluating models (Yao et al. 2009; Ju et al. 354 2011). 
356 The performance of the four models varied for the cropping systems and fertilization 357 management practices. Consequently, we conclude that neither of the models emerged as a 358 clear "best" choice for estimating $\mathrm{N}_{2} \mathrm{O}$ emissions for Chinese cropping systems. In the short 359 term, it may be best to adopt the methods based on linear regression models to calculate the $360 \mathrm{~N}_{2} \mathrm{O}$ emissions for rice, maize, wheat and soybeans, although even this approach has 361 limitations, leading to significant differences between observed and modelled emissions for 362 cotton, fallow or rape. Further development is needed to represent regional conditions in 363 China associated with dominant soil properties, agricultural practices, cropping systems, and 364 climate conditions, in order to refine empirical models and improve the suitability of process365 based models in Chinese conditions.

\section{Acknowledgments}

367 This work was financially supported by China Natural Science Foundation under a grant number 41501569 and "the Fundamental Research Funds for the Central Universities" under a grant number KJQN201673. This work was also supported by Department of Science and Technology of Jiangsu province under a grant number BK20150684. This work also

371 contributes to the activities of NCircle - a BBSRC-Newton Funded project (BB/N013484/1).

372 The first author thanks the China Scholarship Council (CSC) for funding to support study at 373 University of Aberdeen, UK. 
376 Abdalla, M., Jones, M., Williams, M., 2010a. Simulation of $\mathrm{N}_{2} \mathrm{O}$ fluxes from Irish arable 377 soils: effect of climate change and management. Biol. Fertil. Soils 46,247-260. Abdalla, M., M. Jones, J. Yeluripati, P. Smith, J. Burke, and M. Williams. "Testing DAYCENT and DNDC model simulations of $\mathrm{N} 2 \mathrm{O}$ fluxes and assessing the impacts of climate change on the gas flux and biomass production from a humid pasture." Atmospheric Environment 44.25 (2010): 2961-2970.

Beare M H, Gregorich E G, St-Georges P. 2009. Compactioneffects on $\mathrm{CO} 2$ and $\mathrm{N}_{2} \mathrm{O}$ production during drying andrewetting of soil. Soil Biology Biochemistry, 41, 611-621.

Beheydt, D., Boeckx, P., Sleutel, S., Li, C., \& Van Cleemput, O. (2007). Validation of DNDC for 22 long-term $\mathrm{N} 2 \mathrm{O}$ field emission measurements. Atmospheric Environment, 41(29), 6196-6211.

Bouwman, A.F., L.J.M. Boumans, and N.H. Batjes. 2002a. Modelingglobal N2O and NO emissions from fertilized fields. Global Biogeochem.Cycles 16, doi:10.1029/2001GB001812.

Bouwman, A.F., L.J.M. Boumans, and N.H. Batjes. 2002b. Emissionsof N2O and NO from fertilized fields: Summary of availablemeasurement data. Global Biogeochem. Cycles 16, doi:10.1029/2001GB001811.

Cai, Z., Swamoto, T., Li, C., Kang, G., Boonjawat, J., Mosier, A.,Wassmann, R., Tsuruta, H.,2003. Field validation of the DNDC-model for greenhouse gas emissions in EastAsian cropping systems. Global Biogeochemical Cycles 17, 1107.

Cheng, K., Ogle, S. M., Parton, W. J., \& Pan, G. (2013). Predicting methanogenesis from rice paddies using the DAYCENT ecosystem model. Ecological modelling, 261, 19-31. 

biogeochemicaleffects and best management practice for a wheat-maize cropping systemusing the DNDC model. Biogeosciences 11, 91-107.

400

Dobbie, K.E., McTaggart, I.P., Smith, K.A., 1999. Nitrous oxideemissions from intensive agricultural systems: variationsbetween crops and seasons, key driving variables, and meanemission factors. Journal of Geophysical Research 104,26891-26899.

Del Grosso S J, Parton W J, Mosier A R, et al. DAYCENT national-scale simulations of 404 nitrous oxide emissions from cropped soils in the United States. Journal of Environmental quality, 2006, 35(4): 1451-1460.

Del Grosso, S. J., Ojima, D. S., Parton, W. J., Stehfest, E., Heistemann, M., DeAngelo, B., \& Rose, S. (2009). Global scale DAYCENT model analysis of greenhouse gas emissions and mitigation strategies for cropped soils. Global and Planetary Change, 67(1), 44-50.

Dobbie, K.E., Smith, K.A., 2001. The effects of temperature, water filled pore spaceand land use on N2O emissions from imperfectly drained gleysol. EuropeanJournal of Soil Science 52, 667-673.

Frolking S E, Mosier A R, Ojima D S, et al. Comparison of N2O emissions from soils at three temperate agricultural sites: simulations of year-round measurements by four models.

414 Nutrient Cycling in Agroecosystems, 1998, 52(2): 77-105.

Flessa, H., Ruser, R., Schilling, R., Loftfield, N., Munch, J. C., Kaiser, E. A., \& Beese, F. 416 (2002). N $2 \mathrm{O}$ and $\mathrm{CH} 4$ fluxes in potato fields: automated measurement, management effects and temporal variation. Geoderma, 105(3), 307-325. temporal patterns at the landscape and seasonal scales. Soil Biology and Biochemistry, 1989, 

Processes and factorscontrolling $\mathrm{N} 2 \mathrm{O}$ production in an intensively managedlow carbon calcareous soil under sub-humid monsoonconditions. Environmental Pollution, 159, 10071016.

Hu, L. I., QIU, J. J., WANG, L. G., XU, M. Y., LIU, Z. Q., \& Wei, W. A. N. G. (2012). Estimates of $\mathrm{N} 2 \mathrm{O}$ emissions and mitigation potential from a spring maize field based on DNDC model. Journal of Integrative Agriculture, 11(12), 2067-2078.

Janssens-Maenhout, G., et al. (2017) "Fossil CO2 and GHG emissions of all world countries."

Lessard, R., Rochette, P., Gregorich, E. G., Pattey, E., \& Desjardins, R. L. (1996). Nitrous oxide fluxes from manure-amended soil under maize. Journal of Environmental Quality, 25(6), 1371-1377.

Li, C., Farahbakhshazad, N., Jaynes, D. B., Dinnes, D. L., Salas, W., \& McLaughlin, D. (2006). Modeling nitrate leaching with a biogeochemical model modified based on observations in a row-crop field in Iowa. Ecological modelling, 196(1), 116-130.

Li C, Zhuang Y, Cao M, et al. Comparing a process-based agro-ecosystem model to the IPCC methodology for developing a national inventory of $\mathrm{N} 2 \mathrm{O}$ emissions from arable lands in China. Nutrient Cycling in Agroecosystems, 2001, 60(1): 159-175.

Li, H., Wang, L., Li, J., Gao, M., Zhang, J., Zhang, J., ... \& Frolking, S. (2017). The development of China-DNDC and review of its applications for sustaining Chinese agriculture. Ecological Modelling, 348, 1-13. 
Sansoulet, J., Pattey, E., Kröbel, R., Grant, B., Smith, W., Jégo, G., ... \& Tremblay, G. (2014).

Comparing the performance of the STICS, DNDC, and DAYCENT models for predicting N uptake and biomass of spring wheat in Eastern Canada. Field Crops Research, 156, 135-150.

Shcherbak I, Millar N, Robertson GP. Global metaanalysis of the nonlinear response of soil nitrous oxide (N2O) emissions to fertilizer nitrogen. Proceedings of the National Academy of Sciences. 2014;111(25):9, 199-204.

Smith W N, Grant B B, Desjardins R L, et al. Evaluation of two process-based models to estimate soil N2O emissions in Eastern Canada. Canadian Journal of Soil Science, 2008, 88(2): 251-260.

Smith W N, Desjardins R L, Grant B, et al. Testing the DNDC model using N2O emissions at two experimental sites in Canada. Canadian Journal of Soil Science, 2002, 82(3): 365-374.

Weier K L, Doran J W, Power J F, et al. Denitrification and the dinitrogen/nitrous oxide ratio as affected by soil water, available carbon, and nitrate. Soil Science Society of America Journal, 1993, 57(1): 66-72.

Xu, W., Luo, X.S., Pan, Y.P., Zhang, L., Tang, A.H., Shen, J.L., Zhang, Y., Li, K.H., Wu,

Q.H., Yang, D.W. and Zhang, Y.Y., 2015. Quantifying atmospheric nitrogen deposition 461 through a nationwide monitoring network across China. Atmospheric Chemistry and Physics, 462 15(21), pp.12345-12360.

463 Yu, Y., Tao, H., Jia, H., \& Zhao, C. (2017). Impact of plastic mulching on nitrous oxide emissions in China's arid agricultural region under climate change conditions. Atmospheric Environment, 158, 76-84. 
466 Zhang, S., Pu, Z., Li, J., 2013. The spatial-temporal variation of sunshine duration in Xinjiang 467 during 1961-2010. Acta Geogr. Sin. 68, 1481-1492.

468 
469 Table captions

470 Table 1 Models inputs for models simulation.

471 Table 2 Statistics describing the performance of DAYCENT and DNDC model in grain yield

472 simulations.

473 Table 3 Information of sites selected for simulating daily fluxes of $\mathrm{N}_{2} \mathrm{O}$ emissions.

474 Table 4 The performance of four models in estimating $\mathrm{N}_{2} \mathrm{O}$ emissions under different 475 fertilizer management

476 Table 5 The performance of four models for estimating $\mathrm{N}_{2} \mathrm{O}$ emissions associated with crop 477 types

478 Table 6 Statistics describing the correlations of observed or simulated $\mathrm{N}_{2} \mathrm{O}$ emissions with 479 nitrogen fertilizer application rates in Fig. 4.

480 
482 Fig.1 Comparison of measured and simulated crop yields for experimental sites across China

483 Fig. 2 Comparison of observed and modeled daily patterns of $\mathrm{N}_{2} \mathrm{O}$ emissions from rice paddy 484 sites. (The representation of letters "a" to "e" were explained in Table 3)

485 Fig. 3 Comparison of observed and simulated cumulative $\mathrm{N}_{2} \mathrm{O}$ emissions for four models

486 Fig. 4 Comparison of observed and modelled growing season $\mathrm{N}_{2} \mathrm{O}$ emissions from a range of 487 nitrogen fertilizer application rates (a, rice paddy; b, upland) 
Table 1 Models input data for models simulation.

\begin{tabular}{|c|c|c|c|c|}
\hline Data items & DAYCENT & DNDC & LRM & IPCC \\
\hline $\begin{array}{l}\text { Geographical } \\
\text { location }\end{array}$ & Longitude; Latitude; & Latitude & / & / \\
\hline Climate factors & $\begin{array}{l}\text { Daily maximum temperature; daily } \\
\text { minimum temperature; daily } \\
\text { precipitation; N decomposition; }\end{array}$ & $\begin{array}{l}\text { The same as for } \\
\text { DAYCENT }\end{array}$ & $\begin{array}{l}\text { Annual average } \\
\text { temperature }\end{array}$ & / \\
\hline Soil properties & $\begin{array}{l}\text { SOC; } \mathrm{C} / \mathrm{N} \text { ratio; soil clay, silt, sand } \\
\text { content; soil bulk density; } \mathrm{pH}\end{array}$ & $\begin{array}{l}\text { The same as for } \\
\text { DAYCENT }\end{array}$ & Soil clay content & / \\
\hline Growing time & $\begin{array}{c}\text { Crop type; sowing date; harvested } \\
\text { date; }\end{array}$ & $\begin{array}{l}\text { The same as for } \\
\text { DAYCENT }\end{array}$ & Crop type & / \\
\hline $\begin{array}{l}\text { Management } \\
\text { practices }\end{array}$ & $\begin{array}{l}\mathrm{N} \text { applied rate, date and type; } \\
\text { irrigating amount and date; tillage } \\
\text { intensity and date; straw returning } \\
\text { amount }\end{array}$ & $\begin{array}{l}\text { The same as for } \\
\text { DAYCENT }\end{array}$ & $\begin{array}{l}\mathrm{N} \text { rate } ; \mathrm{N} \text { fertilizer } \\
\text { type }\end{array}$ & $\mathrm{N}$ rate \\
\hline
\end{tabular}

"/": The parameters were not required to be entered. 
Table 2 Statistics describing the performance of DAYCENT and DNDC model in grain yield simulations.

\begin{tabular}{cccccc}
\hline Items & Models & R-square & RMSE & Bias & t-test \\
\hline \multirow{2}{*}{ Yield } & DAYCENT & 0.64 & 2201 & -823 & $\mathrm{~s}$ \\
& DNDC & 0.71 & 2088 & -578 & $\mathrm{~s}$ \\
\cline { 2 - 6 } & DAYCENT & 0.14 & 1.35 & -0.15 & $\mathrm{~ns}$ \\
\multirow{2}{*}{$\mathrm{N}_{2} \mathrm{O}-\mathrm{N}$} & DNDC & 0.14 & 1.48 & -0.52 & $\mathrm{~s}$ \\
& LRM & 0.23 & 1.22 & -0.02 & $\mathrm{~ns}$ \\
& IPCC & 0.15 & 1.42 & -0.09 & $\mathrm{~ns}$ \\
\hline
\end{tabular}


Table 3 Information of sites selected for simulating daily fluxes of $\mathrm{N}_{2} \mathrm{O}$ emissions.

\begin{tabular}{cccccc}
\hline Site & $\begin{array}{c}\text { Latitude, } \\
\text { Longitude }\end{array}$ & Region & $\begin{array}{c}\text { Cropping } \\
\text { system }\end{array}$ & $\begin{array}{c}\text { Typical N fertilizer } \\
\text { rate (kg ha-1) }\end{array}$ & References \\
\hline Heilongjiang (a) & $47.4^{\circ}, 126.6^{\circ}$ & Northeast China & RP & 95.4 & Yue et al., 2005 \\
Hunan (b) & $28.6^{\circ}, 113.3^{\circ}$ & $\begin{array}{c}\text { South-Central } \\
\text { China }\end{array}$ & RP-RP & 135(RP), 135(RP) & Wang et al., 2014 \\
Liaoning (c) & $41.8^{\circ}, 123.6^{\circ}$ & Northeast China & MA & 160 & Cheng et al., 2016 \\
Hebei (d) & $40.0^{\circ}, 118.1^{\circ}$ & North China & MA & 180 & Lu et al., 2015 \\
Jiangsu (e) & $32.0^{\circ}, 118.8^{\circ}$ & East China & RP-WH & 250(RP), 250(WH) & Zhou et al., 2016 \\
\hline
\end{tabular}


Table 4 The performance of four models in estimating $\mathrm{N}_{2} \mathrm{O}$ emissions under different fertilizer management

\begin{tabular}{ccccc}
\hline Fertilizer type & Model & RMSE & Bias & t-test \\
\hline \multirow{4}{*}{ No fertilizer } & DAYCENT & 0.81 & -0.21 & $\mathrm{~s}$ \\
& DNDC & 0.87 & -0.51 & $\mathrm{~s}$ \\
& LRM & 0.73 & 0.16 & $\mathrm{~s}$ \\
\cline { 2 - 5 } Mineral & DAYCENT & 1.52 & -0.06 & $\mathrm{~ns}$ \\
fertilizer & DNDC & 1.71 & -0.66 & $\mathrm{~s}$ \\
& LRM & 1.37 & -0.16 & $\mathrm{~ns}$ \\
& IPCC & 1.50 & -0.07 & $\mathrm{~ns}$ \\
\cline { 2 - 5 } Organic & DAYCENT & 0.53 & 0.01 & $\mathrm{~ns}$ \\
fertilizer & DNDC & 0.54 & -0.15 & $\mathrm{~ns}$ \\
& LRM & 0.77 & 0.41 & $\mathrm{~s}$ \\
& IPCC & 1.65 & 1.40 & $\mathrm{~s}$ \\
\hline
\end{tabular}


Table 5 The performance of four models for estimating $\mathrm{N}_{2} \mathrm{O}$ emissions associated with crop types

\begin{tabular}{|c|c|c|c|c|c|c|c|c|c|}
\hline $\begin{array}{l}\text { Crop } \\
\text { type }\end{array}$ & Model & RMSE & Bias & $\mathrm{t}$-test & $\begin{array}{l}\text { Crop } \\
\text { type }\end{array}$ & Model & RMSE & Bias & t-test \\
\hline \multirow{4}{*}{ Rice } & DAYCENT & 1.02 & 0.11 & ns & \multirow{4}{*}{ Cotton } & DAYCENT & 3.14 & -3.10 & $\mathrm{~S}$ \\
\hline & DNDC & 1.00 & -0.41 & $\mathrm{~s}$ & & DNDC & 4.43 & -4.25 & s \\
\hline & LRM & 0.93 & -0.04 & ns & & LRM & 3.54 & -3.39 & $\mathrm{~s}$ \\
\hline & IPCC & 0.94 & -0.34 & $\mathrm{~s}$ & & IPCC & 2.34 & -2.34 & ns \\
\hline \multirow{4}{*}{ Maize } & DAYCENT & 1.68 & -0.32 & ns & \multirow{4}{*}{ Fallow } & DAYCENT & 1.46 & -1.09 & $\mathrm{~s}$ \\
\hline & DNDC & 1.72 & -0.51 & $\mathrm{~s}$ & & DNDC & 1.51 & -1.26 & s \\
\hline & LRM & 1.38 & -0.16 & $\mathrm{~ns}$ & & LRM & 1.21 & -0.73 & $\mathrm{~s}$ \\
\hline & IPCC & 1.64 & 0.05 & ns & & IPCC & 2.04 & -1.72 & $\mathrm{~s}$ \\
\hline \multirow{4}{*}{ Wheat } & DAYCENT & 1.19 & -0.06 & $\mathrm{~ns}$ & \multirow{4}{*}{ Rape } & DAYCENT & 0.69 & 0.35 & ns \\
\hline & DNDC & 1.33 & -0.55 & $\mathrm{~s}$ & & DNDC & 1.54 & -1.33 & $\mathrm{~s}$ \\
\hline & LRM & 1.29 & 0.48 & $\mathrm{~s}$ & & LRM & 0.86 & 0.73 & $\mathrm{~s}$ \\
\hline & IPCC & 1.56 & 0.52 & $\mathrm{~s}$ & & IPCC & 0.46 & -0.09 & ns \\
\hline \multirow{4}{*}{ Soybean } & DAYCENT & 0.89 & -0.44 & $\mathrm{~ns}$ & & & & & \\
\hline & DNDC & 0.59 & -0.13 & ns & & & & & \\
\hline & LRM & 0.99 & -0.58 & ns & & & & & \\
\hline & IPCC & 0.85 & -0.59 & $\mathrm{~ns}$ & & & & & \\
\hline
\end{tabular}


Table 6 Statistics describing the correlations of observed or simulated $\mathrm{N}_{2} \mathrm{O}$ emissions with nitrogen fertilizer application rates in Figure 4.

\begin{tabular}{ccccccc}
\hline & \multicolumn{3}{c}{ Paddy rice } & \multicolumn{3}{c}{ Upland crop } \\
\hline Slope & intercept & R-square & Slope & intercept & R-square \\
\hline Observed & 0.0034 & 0.3180 & 0.1250 & 0.0042 & 0.8404 & 0.1174 \\
DAYCENT & 0.0042 & 0.3270 & 0.2383 & 0.0046 & 0.4888 & 0.3872 \\
DNDC & 0.0027 & -0.0243 & 0.3418 & 0.0056 & 0.0561 & 0.3316 \\
LRM & 0.0018 & 0.4722 & 0.4522 & 0.0039 & 0.8809 & 0.4463 \\
\hline
\end{tabular}




\section{Fig.1}

Click here to download high resolution image
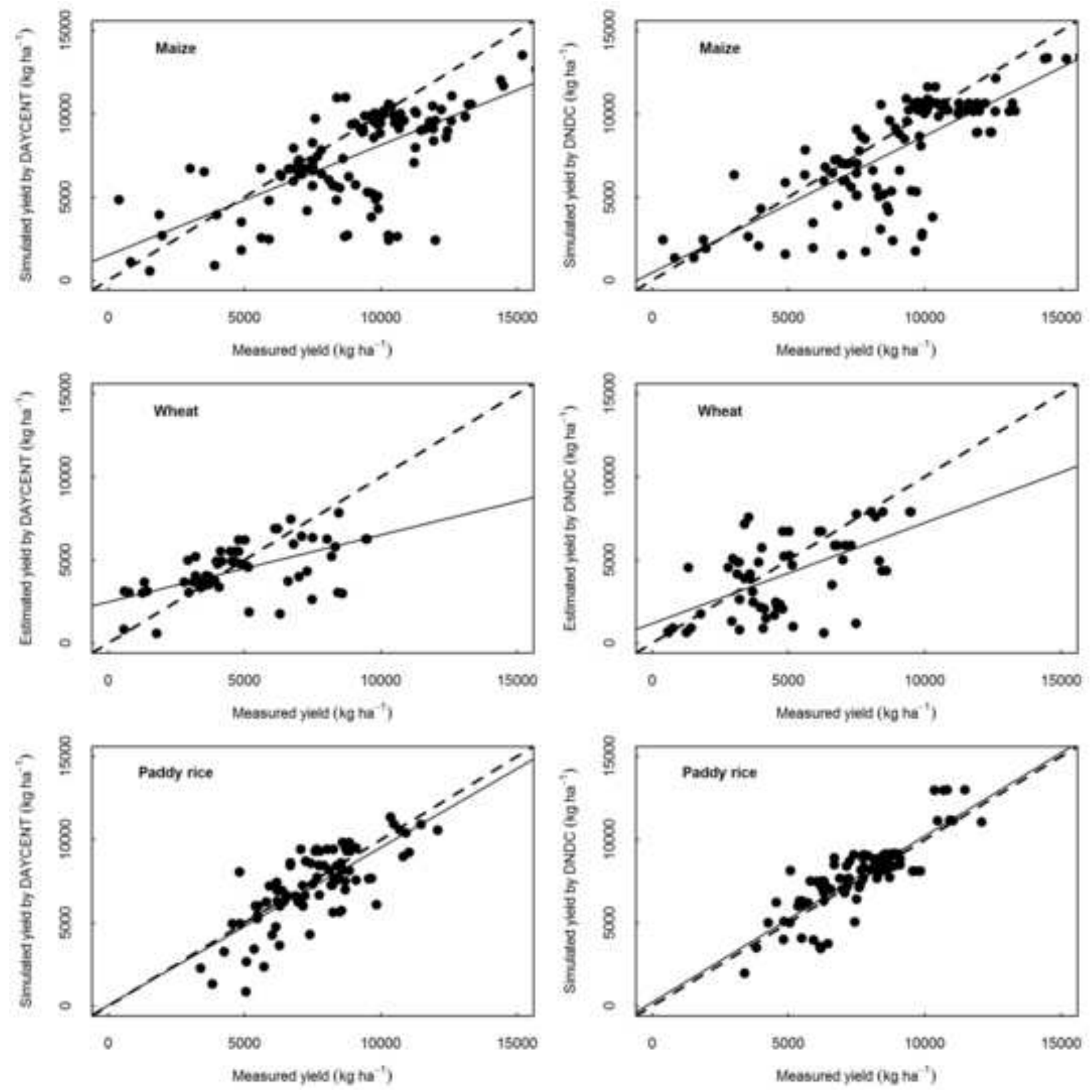
Click here to download high resolution image
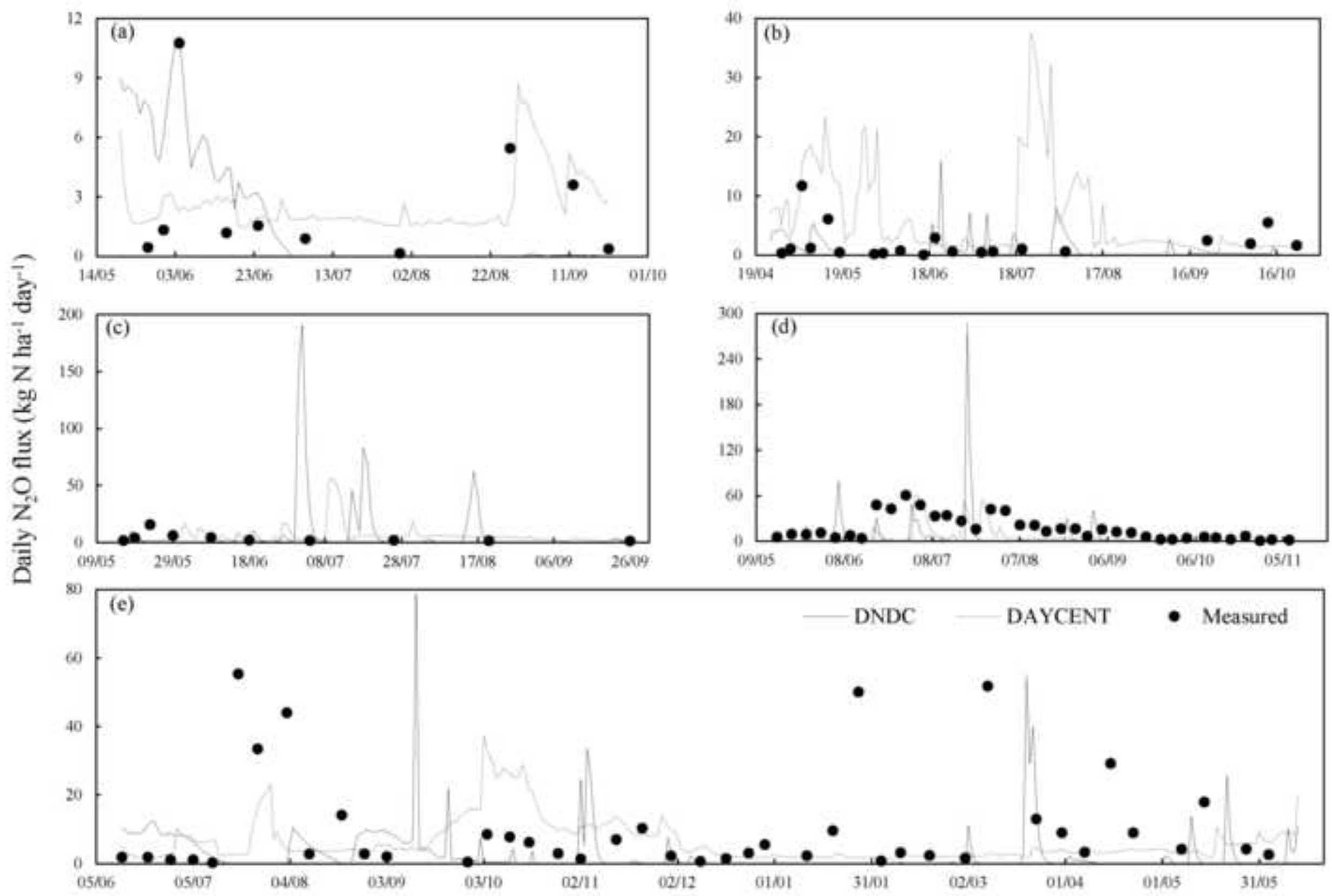

Time ( $\mathrm{dd} / \mathrm{mm})$ 
Fig.3

Click here to download high resolution image
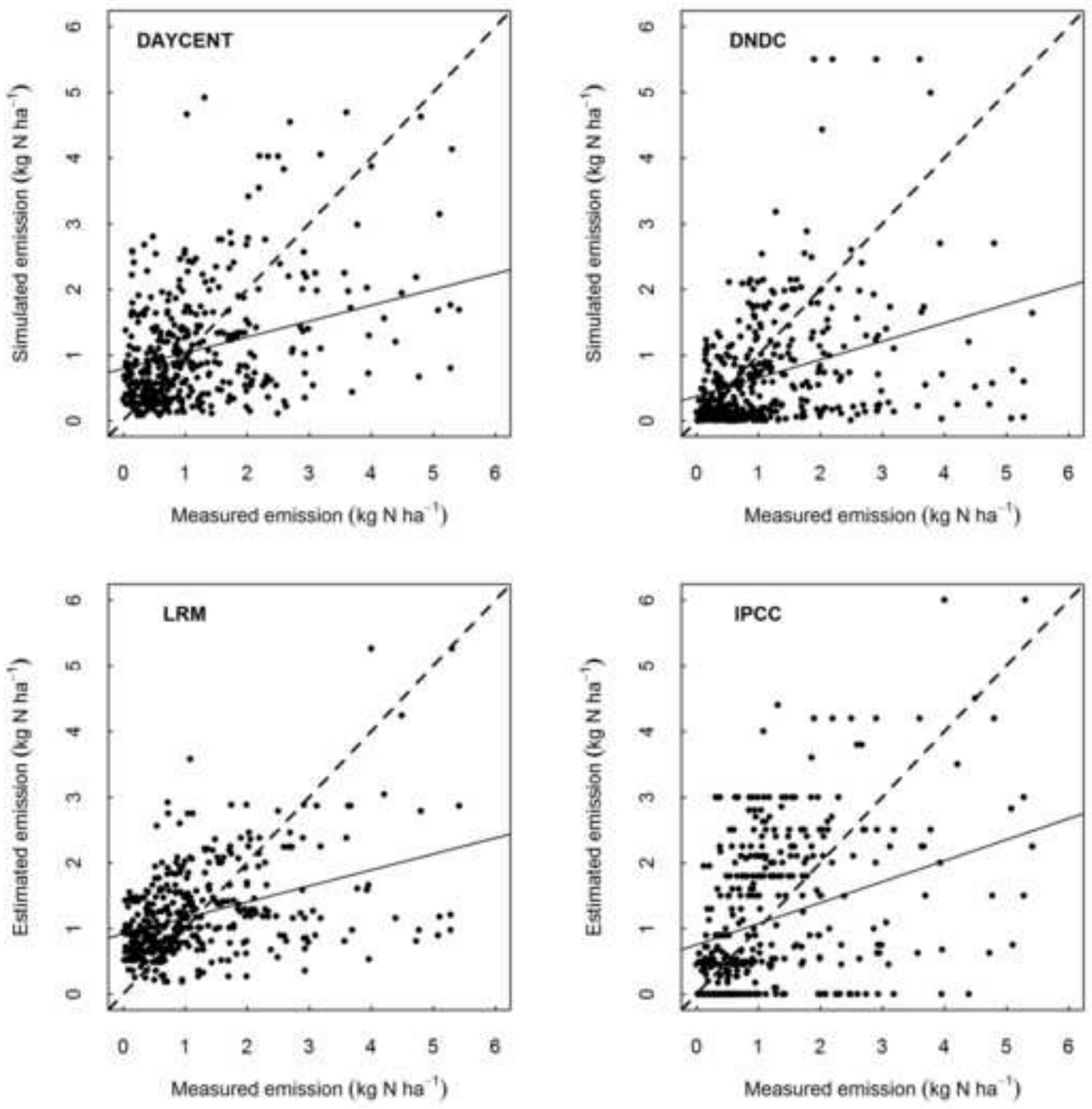
Click here to download high resolution image
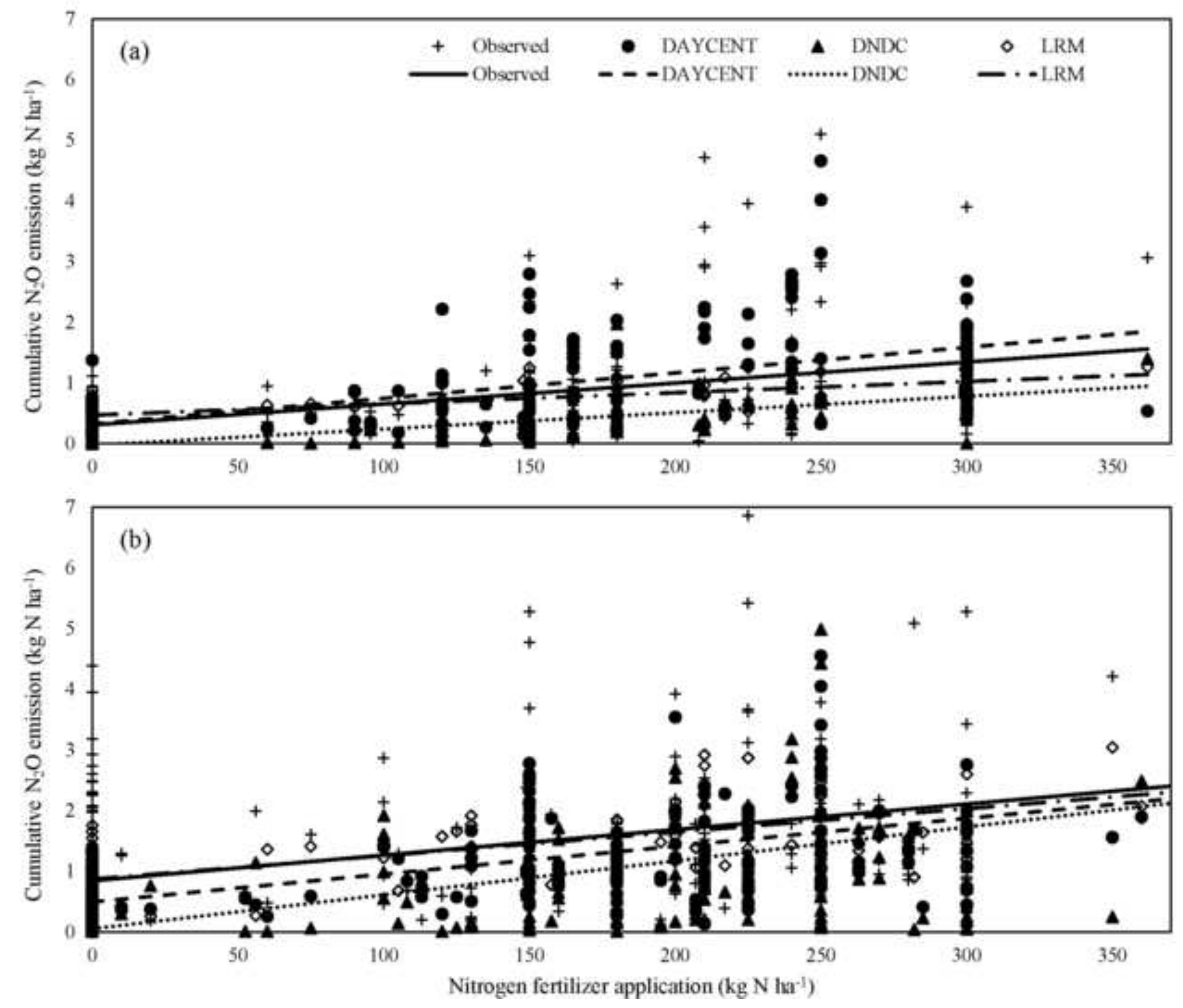
Table S1

Click here to download Supplementary material for on-line publication only: Supplementary material_Table S1.xIsx 
Data in Brief
Click here to download Data in Brief: Data.zip Click here to download Data in Brief: Data.zip

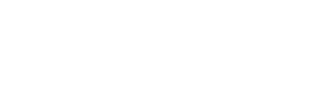

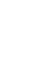

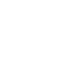

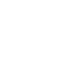

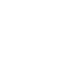

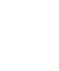
$\sqrt{2}$ (1) (1) (1)

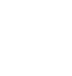

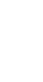
(1) (1) (1) ( . 政 政

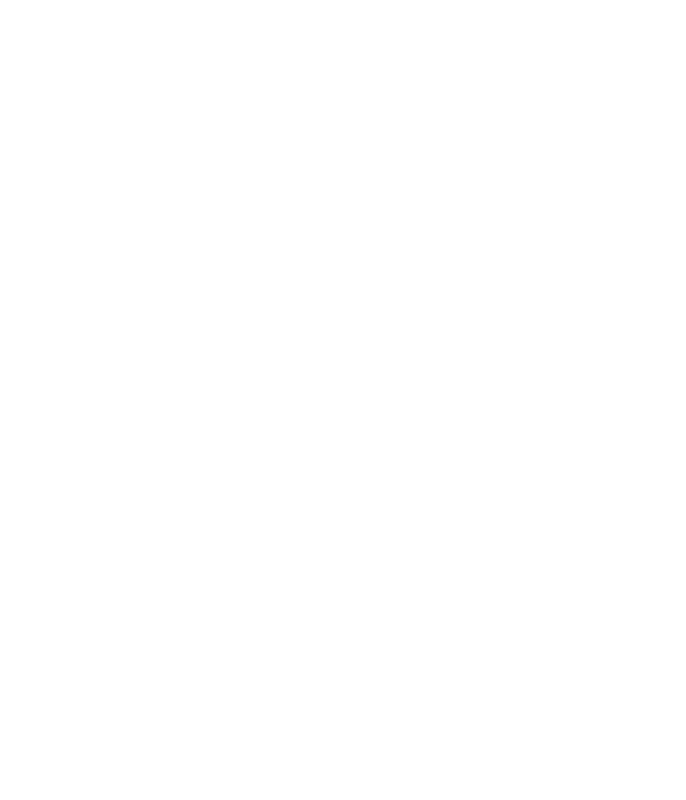
.

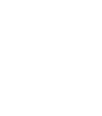

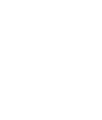

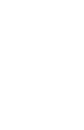

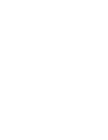

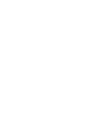
(1)

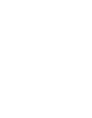

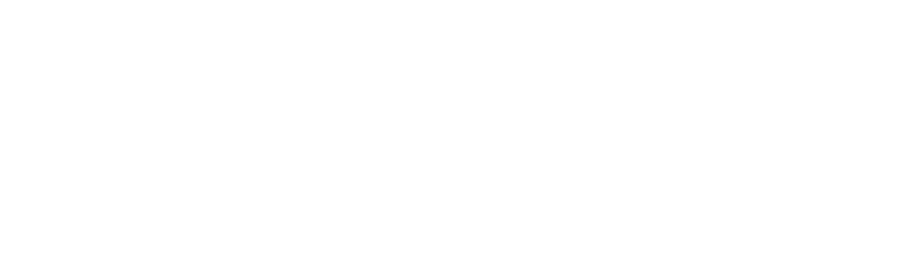
. .

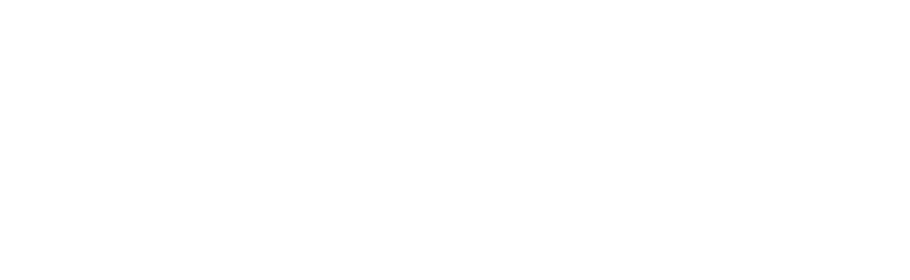

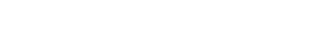
. .

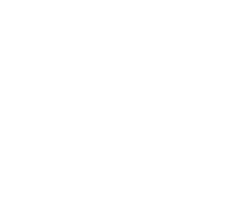
.

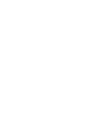
.

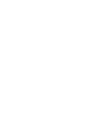

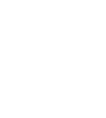

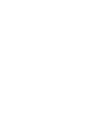

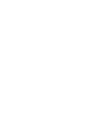

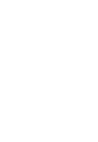

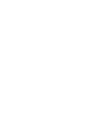

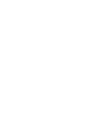
.

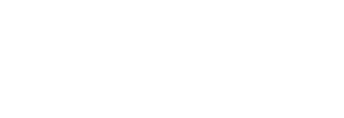

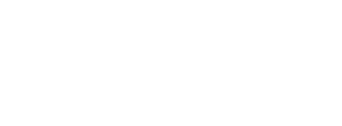

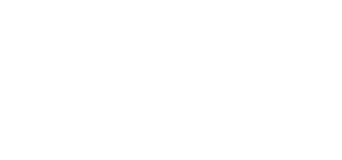
( (1) (

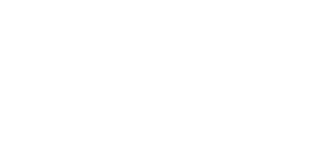
(1)

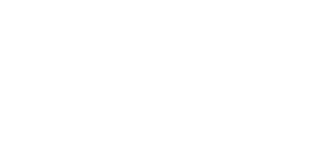

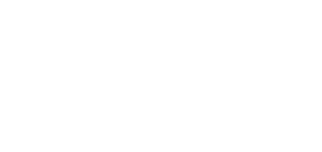

